\title{
Digital technology risk reduction mechanisms to enhance ecological and human safety in the northern sea route for oil and gas companies
}

\author{
Ishel Bianco ${ }^{1}$, Igor $\mathrm{Ilin}^{2}$, and Alexander Iliinsky $^{2, *}$ \\ ${ }^{1}$ University of Maryland USA, Maryland, USA \\ ${ }^{2}$ Peter the Great St. Petersburg Polytechnic University, St. Petersburg, Russia
}

\begin{abstract}
Climate change has removed large quantities of ice and has removed impediments to Arctic sea navigation and in doing so has opened up a new route. Most of these ice-free routes can be used for navigation including oil and gas logistics and transportation and reducing transit by more than 5000 nautical miles. While these events allow for a widening of transportation routes but many challenges naturally inherent to the Arctic are still present, for example, the risk of possible oil spills in the very sensitive ecosystem and the safety risks to crew and equipment. New Technology offers more thorough ways to minimize and manage this risk and to preserve the integrity of ecosystems, safety of people and the profits of companies where operations are more cost sensitive and difficult than in other regions of the world. This paper proposes one model of risk reduction and evaluates the best ways to reduce ecological and safety risks of oil and gas companies operating in the Arctic route. It also proposes methods to incorporate digital value into the organization through four sectors, Sustainability, Efficiency, Accountability and Profitability.
\end{abstract}

\section{Introduction}

The northern route, including Alaska, Canada, and Russia, is the shortest way to connect Europe and Asia. This route has been, for most of modern history, covered by ice. Climate change has opened new parts of that route to transportation. Oil and gas companies can take advantage of these new routes to respond to changes in demand, particularly in liquified natural gas, condensates, and oil products, due to the growing demand of Asian markets. This route has also been proven safer than African routes because to lower piracy and better infrastructure than in African regions.

The Actuality of this research is the need for oil companies to become stewards of natural resources including in the ecologically sensitive and challenging areas like the Arctic safely. The conjunction of benefits is that new technologies like connectivity, Artificial intelligence and Machine Learning can not only improve ecological safety; it can also create profits for Oil and Gas companies by reducing risk, losses and make logistic processes more efficient.

\footnotetext{
*Corresponding author: iliinskij_aa@spbstu.ru
} 
The Goal of this research is to propose technology based strategies to minimize the risks of spills and accidents in the Northern Route for Oil and Gas companies which could jeopardize human health and the ecological balance of the region.

Although there are large pipeline networks connecting Arctic regions to Russia, and more have been recently built by Gazprom, until the recent crisis there was a very responsive market for liquified natural gas that companies such as Novatek have explored [2]. There are high risks to transportation in the Northern Sea Route, such as strong winds and currents [3]. This paper seeks to classify the risks and evaluate their minimization.

\section{Materials and Methods}

This paper uses resources drawn from government research sources, the Arctic council, universities, corporate sources, and academic materials. Since research on Arctic themes is in the early stages of development, some non-Arctic sources are used by proxy to create a more detailed model.

One of the most important sources of this research was produced by the Arctic Council in 2009. The Arctic Council Document includes descriptions of Arctic conditions and its social, cultural, government, ecological, and economic dimensions. The Arctic Council Document represents the most thorough study into the factors driving the transformation of the Arctic through the opening of northern routes for trade and commerce. The Arctic Council Document has been used together with updated sources that better describe current conditions. This article emphasizes cultural and social aspects of the newly opened trade routes and the need to support local communities through this transition [4].

The paper titled "The potential economic viability of using the Northern Route" explains the real advantages of the route while mentioning many of the structural problems that might present challenges and can reduce profitability; it highlights the climatic and ecological difficulties and the restraints of the infrastructure and of governance issues. The paper uses different scenarios to quantify some abstract variables and presents Russian as well as North American cases to better illustrate the complications that might occur when estimating economic value [7]. The article "Commercial Arctic shipping through the Northeast Passage: routes, resources, governance, technology, and infrastructure" published by the Journal of Polar Science presents a deep evaluation of the factors influencing the development of the Artic shipping routes and their significance to worldwide markets. This article carefully enumerates the many challenges surrounding Arctic shipping, such as infrastructure, geological conditions and concerns, uncertain ice cover and poorly mapped depth on likely routes and demonstrates the need for careful monitoring near the shelf of Russia. This article also clarifies issues of governance that might further complicate logistics along the Northern route, such as political differences in method for managing the route between the US and Russia, the need for standards to facilitate international cooperation, and the implications of growing Asian markets [3]. The book "Remote Sensing of Sea Ice in the Northern Sea Route: Studies and Applications" provides a comprehensive review of the history of the Northern Sea Routes and of Arctic commercial operations over time, in particular of the development of Arctic ports and infrastructure. It also provides a review of natural ice obstacles along routes and the mechanisms to avoid collisions or detect impediments. It offers a review of the risks from current and wind and how those risks interact with ice formations, as well as instruments to detect and measure both wind and current factors [8].

"Intelligent Digital Oil and Gas fields: Concepts Collaborations and Right Time Decisions" provides an extensive review of the current technologies available for the oil and gas industry, including an array of different types of sensors and connectivity infrastructure compatible with Arctic conditions that can enhance human ecological safety. Arctic operations are very challenging. Winds can topple equipment, currents can derail prospective 
shipping routes, waves can topple and flood equipment and climate factors can alter projections of delivery and maintenance. Furthermore, the harsh climate of the Arctic makes maintenance critical for safe operation.

Ecological Aspect

Migration of marine animals and their natural activities such as feeding and mating can cause interference with operations due to the relatively small amount of species that are adapted to particular Arctic conditions and owing to the lack of information we have about their habits it is important to avoid interference with ecological processes, particularly with those that relate to keystone species such as whales and Polar bears [3]. Accidents in the arctic can have catastrophic consequences that can affect renewable resources such as Fisheries. Fisheries represent 20 to $30 \%$ of the income of the Arctic. The increased transit will also increase pollution and may increase the risk of transportation of invasive species with ballast water [4].

Economic, Social and Cultural characteristics of the Arctic.

The economy of the Arctic zones is dependent on the extraction of minerals: oil, gas and fisheries. While non-renewable resources offer high rents, they also require extensive infrastructure and pose high risks to the ecology and renewable resources of the Arctic. Native populations are heavily dependent on a small pool of renewable resources, not only economically, but also culturally and spiritually, and these populations should be safeguarded [5].

The development of the North Passage will require a higher investment in infrastructure, but projections suggest that this can double transportation and translate to $\$ 52$ billion in profits [6]. These profits can lead to higher employment for both local populations and migrant workers. Increased economic activity will increase pressure on infrastructure, for example ports in low population density artic regions in Canada and the US. Russia has several functioning ports along these routes however some need to be updated [7].

"Environmental Sustainability and Accountability" provides a novel framework to analyze the impacts of the extractive industries on renewable resources and the communities that depend on these renewable resources. This source seeks to quantify the cost of many extractive and industrial processes, and to quantify the risks for natural resources. The book presents a small review of cases that are consistent with the costs of resource intensive industries like oil and gas [9].

"Bits, Bytes, and Barrels: The Digital Transformation of Oil and Gas" illustrates the digital transformation and challenges of the oil and gas industry in adapting to the increasing pace of change. The final chapters offer a review of technologies like cloud and SCADA systems to facilitate the communication needs in the fields and support decision making at companies. This book also describes the opportunities of digital technology to reduce the risks affecting oil and gas companies in challenging environments such as the Arctic [10].

"Resilience engineering" covers many subjects on risk reduction and discusses the most important built-in strategies that can reduce catastrophic events in challenging situations. This resource discusses at length the factors within organizations that exacerbate conditions that can lead to accidents. The book addresses the deeper principles of risk like sources of vulnerability and how to manage them effectively. It has several different chapters that explain what makes companies prone to both these vulnerabilities and human error, which is the leading cause of oil and gas accidents.

The article, "Low cost remote sensing technologies in the Arctic" presents the availability of many technologies that provide monitoring of chemicals and activities under Arctic conditions. Some of these technologies have not been extensively tested, and therefore might need further investment to evaluate their reliability under cold climate and in ecologically vulnerable regions for larger periods of time. These technologies are highly adaptable and can decrease risk and increase safety in a variety of operating areas, from operations to 
disposal and transportation. Low cost oceanographic probes like ArLoC (Arctic Low Cost Probe) have been deployed on the Proteus platform with great success and accuracy $[11,12]$.

This model identifies several risks factors, assigns them a weight, proposes an equation to measure risk, and modifies this risk by reducing risk factors to propose a full risk assessment that accounts for risk more accurately than previous models. Although there is insufficient data on oil spills in the Arctic for novel operations in the North Passage this paper incorporates historical data under similar operating conditions (season, type of equipment).

New technologies have caused a revolution in the oil and gas technology. Digital technologies in particular have led to higher efficiency, transparency and become the fuel of further innovation that have transformed all industries, particularly logistics [13]. This revolution has affected planning, extraction, transportation and refining operations in the oil and gas industry. The most influential technologies in the oil and gas industry pertain to real time operations; significantly reducing risk by providing more accurate measurements and better communication between sensors and managing operations, further improving decision making capabilities. Drones and submarine vehicles can better monitor operations in natural conditions [10].

This research is relevant to the evaluation of the effectiveness of oil and gas exploration and transportation of hydrocarbons through the Northern route that connects Northern America and Europe with the West.

Data made available by the World Economic Forum shows that the use of digital tools in the oil industry has reduced accidents by $6 \%$, and predictive maintenance in itself can further reduce accidents by $3 \%$ The use of digital technologies can reduce costs by $10 \%$ to $20 \%$ and has resulted in a reduction of 44, 300 in pipeline spills and 66000 in spills related with extraction operations. Analysts of the World Bank have further indicated that connected workers have reported a reduction of $13 \%$ on accidents at specific sites [14].

This research discusses the challenges and presents a new model of risk minimization that is inclusive of ecological and safety factors.

Investment in technologies to monitor risks factors, such as sensors, need to be significant to be effective. Deployment needs to be localized in the right areas and the technology needs to be resistant to environmental factors that might impede function, such as corrosion, impact, and wildlife activity [8]. In some instances, pollution sensors deployed in Canada have been located in areas less likely to encounter pollution loads, making them ineffective. Scarce, obstructed, or low-sensitivity sensors serve mostly as decoration [15].

Logistic risk is highest at loading, offloading to transportation centers during high winds or during strong currents. Climatic conditions are unpredictable but modern sensors can be located in places where there have been past events and can show early warning in case of recurrence. Furthermore, these sensors can be coordinated with Artificial Intelligence and Machine Learning that can recognize patterns in the data that might indicate a higher risk as it happens. These technologies have been proven to be very useful in ecologically vulnerable zones and where human lives might be at risk [10].

Equipment and human error have been one of the leading causes of industrial and energy disasters. Human error exposure should be minimized by using technologies that manages data and can respond to alerts with more efficacy and monitoring the condition and function of equipment. Resilience and error minimizing engineering from inception to minimize errors and speed recovery.

Oil and Gas related ships have increased transit at the same time and comparable speed as Fishing ships. The significance of an increase of oil related vessels can mean that an accident is more likely to occur, and the higher amount of cargo and shipping vessels that there will be also a higher possibility of both interference to wildlife and collisions, damage to more exploited fisheries is likely to quantify as higher damages, as fisheries represent more than $30 \%$ of the income of some Arctic regions and indigenous nations in the regions with 
lower incomes are more dependent on fishing and make use of other natural resources in zones that might be affected by an accident [16].

The Arctic council has also indicated that there are possibilities of more soft and thin ice as well as small icebergs detaching from larger ice formations which could affect navigation at many times of the year. Since ecosystems tends to expand beyond national territorial boundaries, and effects can also extend beyond the country of point of origin, we recommend to incorporate some considerations on the ecological dynamics presented by the Large Marine Ecosystem Framework to create more accurate risk models particularly in ecologically sensitive zones, 17 of those zones are located in the Arctic. The LME framework combines both ecological, economic and cultural aspects [16].

Technology Deployment. The use of technology has already decreased the number of accidents and the number of barrels of oil spilled. Current sensors can detect leaks on ships before they start, and can map the movements of vulnerable animals, including the quantities of plankton and identify activity, these sensors require to be coordinated with state and company's systems that can make use of the available information to choose and modify routes and to avoid possible accidents and times when there might be interferences with sensitive biological and ecological factors [17].

Organization capabilities that incorporate digitalization are essential to sustainability, Accountability, Efficiency and Profitability for the Oil and Gas industry. The oil and gas industry today has changed through short contracts instead of long contracts and the abundance of information for shareholders, this affects how the Oil and Gas organization creates value.

One of the greatest challenges in the Arctic is the provision of accurate data since the region is difficult to study and until recent times has been rarely studied [19]. The recent disappearance of the ice cover over the northern passage presents new opportunities, but also new risks. Some regions might have more broken ice, minor icebergs, or be icebergs. Satellite, submarine, accosting and aerial detection technologies, such as the use of drones, allows us to better measure icebergs and ice cover [9].

The accuracy of such sensors is linked to their effective use and their integration to predictive maintenance. In this study the measure of accuracy includes effectivity which covers proper quantity, dispersion of sensors, efficiency under Arctic conditions, and resolution to sense the target factors [11].

Another risk factor of operations in the Arctic seas and through the Northern route is the possibility of current interference and wind events that can be very strong during certain times of the year. These events could significantly impede operations and require specific measures. The following factors are incorporated into the calculation of Risk of Operations in the Northern Seas.

This paper proposes a model to calculate the overall Risk for Oil and Gas transportation characteristic of the Northern Route:

1) First we calculate the Cost of Accident or Spill (C) which is defined:

Cost of Accidents $=$ Risk of Lives $(L)^{*}$ Average payment for Risk of Lives $(A v C L)+$ Risk of Loss of property $(P)^{*}$ Average Loss of Property $(A v C P)+$ Collateral effects $(\text { Coll })^{*}$ Average collateral cost $(A v C o l l)+$ Legal costs in country or countries of origination of event $(L e)+$ remediation $($ Rem $)$ - Insurance $($ Ins $)$

$C=\left(L^{*} A v C L\right)+\left(P^{*} A v C P\right)+(C o l l+A v C R)+L e+R e m-I n s$

2) Second the Overall Risk is calculated

Risk of Northern Road for Oil and Gas operations is then defined as:

RiskN $=((\mathrm{Cr}+\mathrm{Wr}+\mathrm{Mig}+\mathrm{Co}+\mathrm{G}+\mathrm{P}) / \mathrm{Ta})+\left(\left(\mathrm{Tr}{ }^{*} \mathrm{Cap}\right) / \mathrm{Mga}\right)+\mathrm{C}+\mathrm{Le}$

Probability that a current will be encountered $(C)+$ Probability that a wind event might occur $(W)+$ Probability that the route chosen coincides with a migration route $(\mathrm{Mig})+$ Total probability of collision with foreign objects for example ships or icebergs of any size (Coll) 
+ Geological Risk meaning the chance of a geological event disrupting the route, as for example the encounter of a new formation, unsuspected change of subsurface structure, movement or displacement $(G)+$ Piracy Risk, defined as the change of transportation vessel criminal interference $(P)$ / by technological accuracy used, satellite, drones, underwater sensors in the ship or the route $(\mathrm{Ta})$ Risk of transportation failure defined as Statistical chance of a spill per type of transportation and by Operator $(\mathrm{Tr}) *$ container capacity $(\mathrm{Cap}) /$ Percentage of Capability of Managing Accident as in removing spill by time $(M g a)+$ Cost $(C)$.

\section{Results}

Our analysis shows that the increased number of ships in the Northern Route presents a greater risks of ballast water contamination, possible spills, collisions with ice bodies and wildlife and other risks such as sound pollution. Not only more vessels are entering the Arctic but they have undertaken longer journeys by almost $75 \%$ according to the Arctic Council's report. These ships navigate through different jurisdictions where they find different environmental systems in spite of common agreements such as UNICLOS. Some of these agreements are voluntary and therefore unevenly enforced [15].

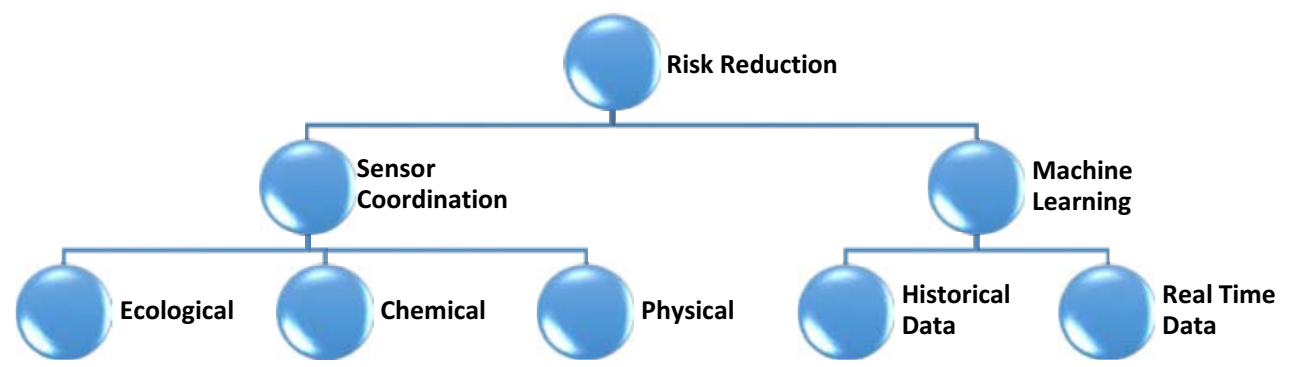

Fig. 1. Flow of smart systems to AI control in Risk Reduction. Source: Authors, Carvajal [9].

The diagram above presents the flow of data from sensors and their incorporation and interpretation by machine learning algorithms and by artificial intelligence systems.

The inclusion of smart sensors and connectivity can reduce accidents and create an effect of value creation where Accountability, Efficiency, inborn sustainability lead to higher profitability Organizational Capabilities.

Organization capabilities that incorporate digitalization are essential to sustainability, Accountability, Efficiency and Profitability for the Oil and Gas industry. The oil and gas industry today has changed through short contracts instead of long contracts and the abundance of information for shareholders, this affects how the Oil and Gas organization creates value.

It is essential to incorporate the digital model in a manner that takes into consideration the particularities of Arctic conditions. These measures could be costly and difficult to at the beginning but in the long term they will lead to efficiencies in all company's sectors. 


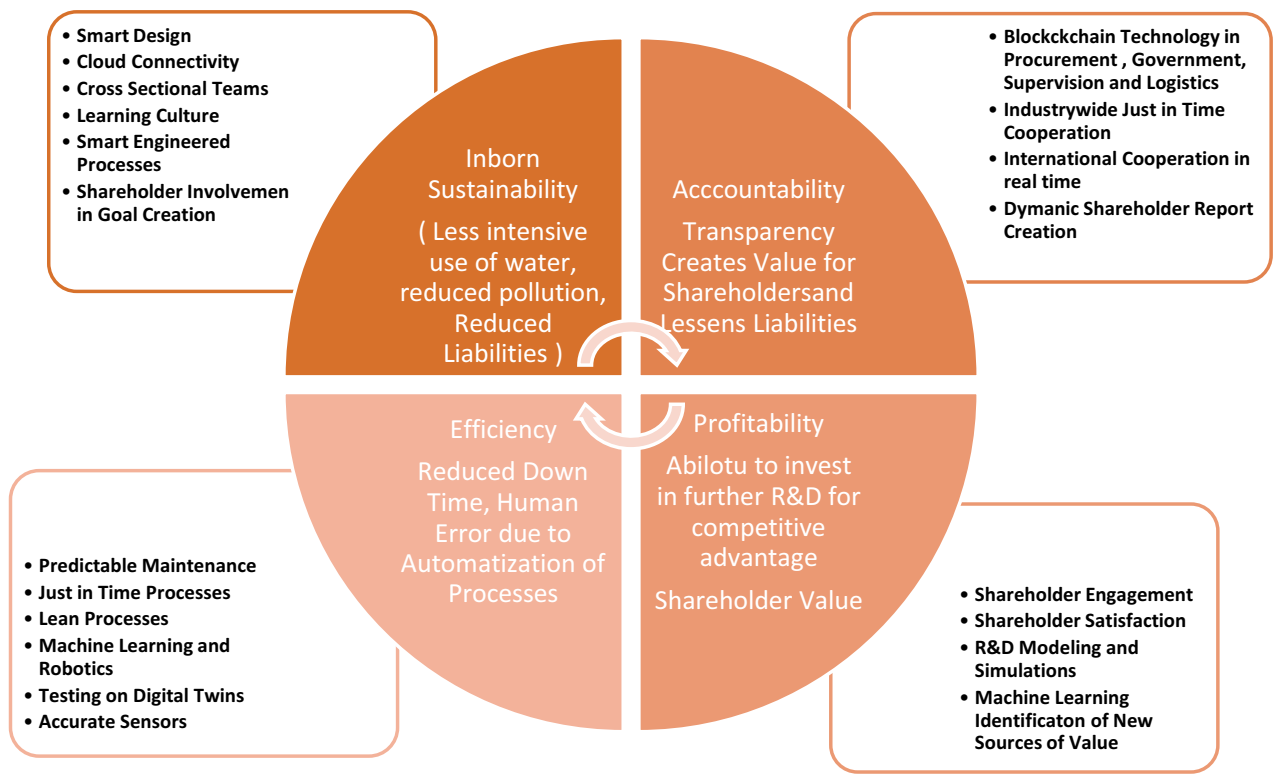

Fig. 2. Components on the Creation of Digital Value. Source, Authors, Maydanova [3].

The above diagram shows the value creation of digital systems in the logistic chain on Oil and Gas operations in the Arctic, The first sector is Inborn sustainability which means that the company is designed smart and sustainable, with connectivity with shareholders, the goals such as reduced waste water, treatment of waste water of vessels are achieved through the tools described.

The Accountability sector creates shareholder value by minimizing risk of exposure to negative events, reducing legal liabilities, reducing error and providing just in time systems, the main tool to do this blockchain technology. The efficiency sector is the most important in the process of digitalization and this is where accurate sensors, predictable maintenance, robotics, Modeling of new production through digital twins. While the goal of a company is profitability a smart company views Profitability also as a sector where digitalization can increase the flow of value to other sectors, in doing so a company maintains competitive advantage by continuous innovation through the use of tools such as Machine learning identification of value centers and new value [18].

Our analysis has shown that a combination of digital connectivity, submarine and aerial sensors might be most sustainable and profitable considering cost of risks.

Due to the high costs of risks of accidents in the Northern Sea, the effects of technology in profits more sharply than in other scenarios [23].

There is a strong need for dynamic risk models that use digital technologies, including scenario development and simulation to overcome the lack of information about Arctic conditions.

Organization capabilities that incorporate digitalization are essential to sustainability, Accountability, Efficiency and Profitability for the Oil and Gas industry. The oil and gas industry today has changed through short contracts instead of long contracts and the abundance of information for shareholders, this affects how the Oil and Gas organization creates value.

The diagram above presents the flow of data from sensors and their incorporation and interpretation by machine learning algorithms and by artificial intelligence systems. 
The inclusion of smart sensors and connectivity can reduce accidents and create an effect of value creation where Accountability, Efficiency, inborn sustainability lead to higher profitability Organizational Capabilities.

Organization capabilities that incorporate digitalization are essential to sustainability, Accountability, Efficiency and Profitability for the Oil and Gas industry. The oil and gas industry today has changed through short contracts instead of long contracts and the abundance of information for shareholders, this affects how the Oil and Gas organization creates value.

High Technology such as accurate sensors widely deployed minimize risks of pollution among Arctic routes. The oil and Gas industry is exposed to more risk than other industries operating in the Northern Sea Route due to potential cost of pollution and accidents during logistic activities [24] High Accuracy sensors and data integration among several areas can be widely deployed since innovation has made technology more affordable.

Our results show that that there is a change on the overall type of transit that occurs in the Arctic and that risk should be modified to properly account for risk, for example although all transport involves fuel, heavier hydrocarbon fuels are less volatile and have a larger time required for biodegradation. There might be a higher risk associated with the location of vessels to sensitive ecosystems, as in fishing vessels near the coast.

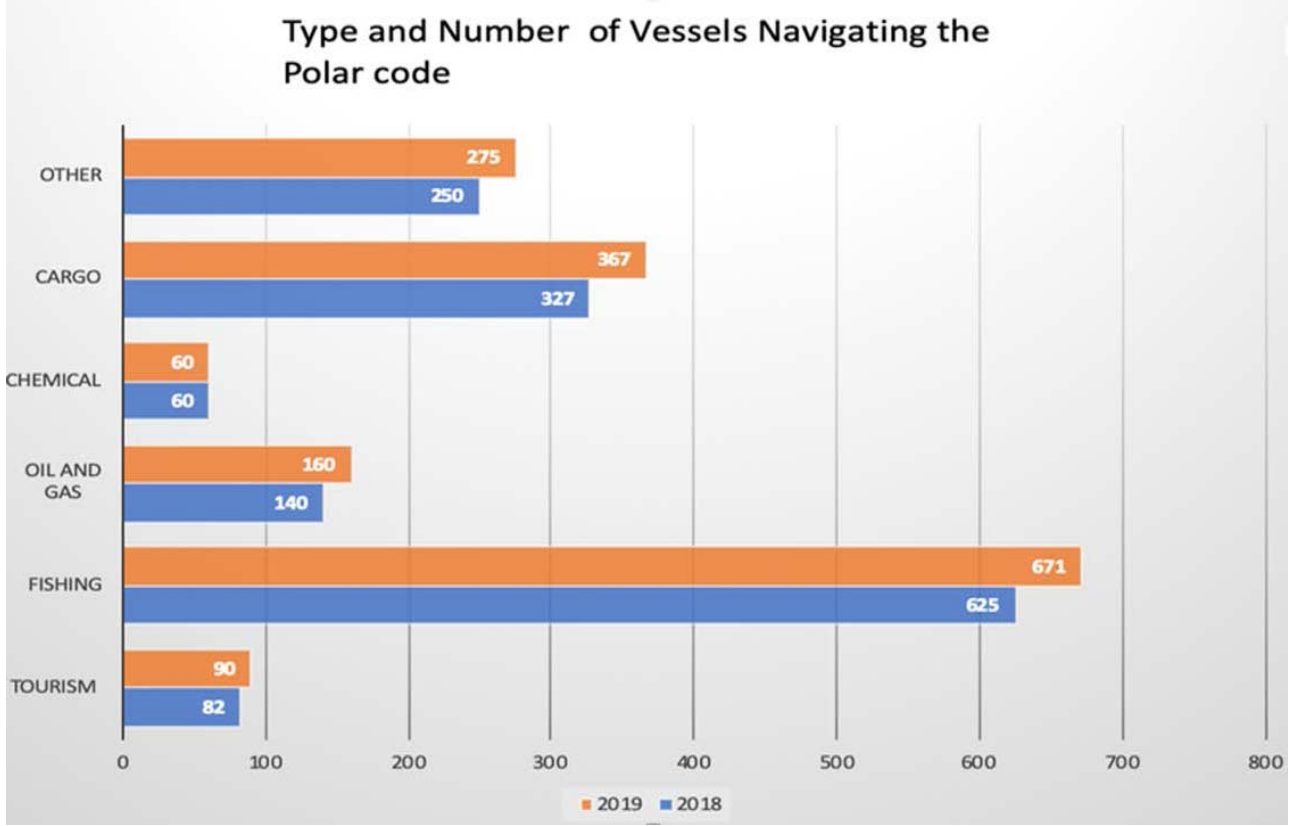

Fig. 3. Transit in the Arctic by quantity and type of ships. Source Authors, PEMA. Arctic Council [4].

Oil and Gas related ships have increased transit at the same time and comparable speed as Fishing ships. The significance of an increase of oil related vessels can mean that an accident is more likely to occur, and the higher amount of cargo and shipping vessels that there will be also a higher possibility of both interference to wildlife and collisions, damage to more exploited fisheries is likely to quantify as higher damages, as fisheries represent more than $30 \%$ of the income of some Arctic regions and indigenous nations in the regions with lower incomes are more dependent on fishing and make use of other natural resources in zones that might be affected by an accident [16]. 


\section{Discussion}

Our model shows that the estimates of the percentage of risk are heavily influenced by the factor of accuracy of measurement. New technologies like submarine vessels can produce very accurate readings of current velocity and wind velocity by sector, and they can also provide real term information about biological factors and measure the activity of animals migrating in the route, therefore reducing collisions. We can use these technologies to reduce the occurrence of catastrophic events. New technologies like unmanned robots, artificial intelligence, and simulations can further refine estimations of risks and data that would not have been otherwise available [2].

Data available by the word bank shows that the use of digital tools in the oil industry has reduced accidents by $6 \%$, costs by $10 \%$ to $20 \%$ and has translated in a reduction of 44,300 in pipeline spills and 66000 in spills related with extraction operations $[6,20]$.

The strength of the model resides in its ability to integrate several variables of risk and quantifies some qualitative variables. This model can be used by oil companies to identify the strengths and weaknesses for prospective transportation projects in the Northern Route. For example, this model can direct a company to invest in more sensors and connectivity solutions to allow for more reliable operations and higher profit by taking advantage of the ice-free routes. It can also reveal when the risk would be too high, or the company would not have enough insurance to undertake operations to adequately bear the risk burden [21].

One of the weaknesses of this model is that it does not allow one exact estimate of the sunk cost of the investment on such technologies. Since investment in such technologies is generally beneficial to operations the authors did not consider that it should have been separately addressed. As an example, the use of connectivity, cloud, and big data technologies would not be a separate investment in the Arctic routes of the logistic expense of the company because it would be applied to overall operations of the company and markets for probes such as Arloc have shown that quality sensors can be obtained at lower cost [11]. Most of the technologies used on oceanographic and geographical processes have decreased in price commensurate with cloud and data solutions [12]. There are also atmospheric sensors that are cost effective and have been developed for arctic conditions, for example AIRQino. The testing of this model requires more data that the researchers hope to acquire in further developments.

Transportation in the Arctic offers several challenges. One of the most significant ones is the high costs of interference and degradation of natural process due to pollution. Legal costs will vary in areas where enforcement or legal burdens of pollution are lower, however, the more relaxed legal systems exposes investors to company negligence and therefore can increase the costs of accidents, as we have seen in The Exxon Valdez oil spill and with BP after the Deepwater Horizon disaster [22].

\section{Conclusions}

1. Our analysis has shown that a combination of digital connectivity, submarine and aerial sensors might be most sustainable and profitable considering cost of risks

2. Due to the high costs of risks of accidents in the Northern Sea, the effects of technology in profits more sharply than in other scenarios [23].

3. A solution is dynamic risk models that use digital technologies, including scenario development and simulation to overcome the lack of information about Arctic conditions.

4. The digital transformation of the Oil and Gas industry requires new, more dynamic and interactive models of value creation to respond to a rapidly changing industry, integrating ecological criteria to minimize costly risks of the Northern Route development. [24] 
5. Since lower ice cover does not mean that the Northern Route becomes less risky overall, because more transit might mean more collisions and interference with species migration which have already been affected by global warming.

6. High Technology such as accurate sensors widely deployed minimize risks of pollution among Arctic routes.

7. The oil and Gas industry is exposed to more risk than other industries operating in the Northern Sea Route due to potential high cost of pollution and accidents during logistic activities [25].

8. High Accuracy sensors and data integration among several areas can be widely deployed since innovation has made technology more affordable and reliable in harsh conditions.

\section{References}

1. S. Maydanova, I. Ilin, A. Lepekhin, Proceedings of the 33rd International Business Information Management Association Conference, IBIMA 2019: Education Excellence and Innovation Management through Vision 2020, 5103-5111 (2019)

2. A. Fadeev, A. Ilynsky, I. Iliyin, IOP Conf. Series: Earth and Environmental Science 539, 012168 (2020)

3. A.F. Buixadé S. Farré, R. Stephenson, et al, Polar Geography 37(4), 298-324 (2014) DOI: $10.1080 / 1088937 X .2014 .965769$

4. Arctic Marine Shipping Report (Arctic Council, 2009) https://web.archive.org/web/20141101021336/http://www.arctic.noaa.gov/detect/docu ments/AMSA_2009_Report_2nd_print.pdf

5. Assessing U.S. preparedness and response in the Arctic: The opportunities and challenges of increased marine activity: Field Hearing Before the Subcommittee on Oceans, Atmosphere, Fisheries and Coast Guard of the Committee on Commerce, Science and Transportation, United States Senate (United States Senate, 2013) http://www.gpo.gov/fdsys/pkg/CHRG-113shrg85764/html/CHRG-113shrg85764.htm

6. H.M. King, What is the Northwest Passage, https://geology.com/articles/northwestpassage.shtml

7. L. Miaojia, J. Kronbak, Journal of Transport Geography 18(3), 434-444 (2010)

8. O.M. Johannessen, V.Y. Alexandrov, I.Y. Frolov, et al, Remote Sensing of Sea Ice in the Northern Sea Route: Studies and Applications (Springer-Praxis, Berlin, Germany, 2007)

9. G. Carvajal, V. Maucec, S. Cullic, Intelligent Digital Oil and Gas Fields (Elsevier science, Kindle Edition, 2018)

10. G. Cann, Bits, Bytes, and Barrels: The Digital Transformation of Oil and Gas (MADCann Press. Kindle Edition, 2019)

11. F. Carotenuto, B. Brilli, B. Gioli, et al, Sensors (Basel) 20(7), 1919 (2020) DOI:10.3390/s20071919 PMCID: PMC7180591

12. V. Piermattei, A. Madonia, S. Bonamano, et al, Sensors (Basel, Switzerland) 18(7), 2257 (2018) https://doi.org/10.3390/s18072257

13. I. Ilyin, A. Levina, A. Borremans, S. Kalyazina, Enterprise Architecture Modeling in Digital Transformation Era (2020) DOI: 10.1007/978-3-030-57453-6

14. World Economic Forum Digital Transformation Initiative in the Oil and Gas industry (2017)https://reports.weforum.org/digitaltransformation/wpcontent/blogs.dir/94/mp/fil es/pages/files/dti-oil-and-gas-industry-white-paper.pdf 
15. S.W. Lee, Benefit and risk of the northern sea route to the north pacific. The Regulation of Continental Shelf Development: Rethinking International Standards (Martinus Nijhoff Piblishers, Leiden Boston, 2013)

16. PAME. Arctic Council. Arctic Shipping Routes Data https://pame.is/projects/arctic-marine-shipping/astd

17. A. Poljanskihh, A. Levina, A. Dubgorn, MATEC Web of Conferences 193, 05065 (2018) DOI: $10.1051 /$ matecconf $/ 201819305065$

18. A. Ilinsky, M. Afanasiev, D. Metkin, IOP Conference Series: Materials Science and Engineering (2019) https://doi.org/10.1088/1757-899X/497/1/012028.

19. S. Véronneau, Journal of Transportation Security 8(3) (2015) DOI: 10.1007/s12198015-0158-6

20. Digitalization can save Oil and Gas 73 billions a year (Reuters, 2019) https://www.reuters.com/article/us-oil-digital-savings-idUSKCN1NH0QR

21. G. Dickle, Oceans Deeply: The New Humanitarian (2014) https://deeply.thenewhumanitarian.org/oceans/articles/2018/03/14/as-the-arctic-meltsnew-technologies-predict-where-sea-ice-will-be

22. G. Shigenaka, Twenty-Five Years After the Exxon Valdez Oil Spill: NOAA's Scientific Support, Monitoring, and Research (NOAA Office of Response and Restoration, Seattle, 2014)

23. Challenges and Solutions for the Digital Transformations and Use of Exponential Technologies

(Deloittle, 2019) https://www2.deloitte.com/content/dam/Deloitte/ch/Documents/manufacturing/ch-enmanufacturing-industry-4-0-24102014.pdf

24. G. Wilkman, T. Mattsson, Development of Icebreaking Ships, in OTC Arctic Technology Conference. Offshore Technology Conference (Google Scholar, 2014)

25. S.G. Svetunkov, Economy of Region 12(3), 966-976 (2016) DOI: 10.17059/2016-3-29 